\title{
SOME REMARKS ON RELATED FIXED POINT THEOREMS
}

\author{
Yumnam Rohen ${ }^{1}$, P.P. Murthy ${ }^{2}$ \\ ${ }^{1}$ Department of Mathematics \\ National Institute of Technology Manipur \\ Langol 795004, INDIA \\ ${ }^{2}$ Department of Applied Mathematics \\ Guru Gasidas University \\ Koni, Bilaspur (Chhatitisgarh) 495009, INDIA
}

\begin{abstract}
In this paper we present a survey of related fixed point theorems in different spaces starting from the results of Fisher. It also includes results in set valued and implicit functions. Regarding the spaces we include metric space, uniform space, fuzzy metric space, menger space, symmetric space, partial metric space etc. Further, we prove two related fixed point theorems in three metric spaces by considering three set valued mappings.
\end{abstract}

AMS Subject Classification: $47 \mathrm{H} 10,54 \mathrm{H} 25$

Key Words: fixed point, common fixed point, related fixed point

\section{Introduction}

Related fixed point theorem was initiated by Brian Fisher (1981). Since then it is extended to various directions by different researchers and as a result of it a flood of research results came out in this area. The extension work goes mainly in two directions. One direction is about the condition of the function used. Important points carried out in this direction are continuity of the mappings, implicit nature and also the number of functions used. Second direction is

Received: January 14, 2016

Published: September 8, 2016

${ }^{\S}$ Correspondence author (c) 2016 Academic Publications, Ltd.

url: www.acadpubl.eu 
about the space in which the related fixed point is to be examined. Regarding the spaces used are complete and compact metric spaces, uniform space, fuzzy metric space, menger space, symmetric space, partial metric space etc.

Following two theorems were proved by Fisher.

Theorem 1.1. (Fisher 1981) [1] Let $\left(X, d_{1}\right)$ and $\left(Y, d_{2}\right)$ be complete metric spaces. If $T$ is a mapping of $X$ into $Y$ and let $S$ is a mapping of $Y$ into $X$ satisfying the inequalities

$$
\begin{aligned}
& d_{2}(T x, T S y) \leq c \max \left\{d_{1}(x, S y), d_{2}(y, T x), d_{2}(y, T S y)\right\} \\
& d_{1}(S y, S T x) \leq c \max \left\{d_{2}(y, T x), d_{1}(x, S y), d_{1}(x, S T x)\right\}
\end{aligned}
$$

for all $x$ in $X$ and $y$ in $Y$, where $0 \leq c<1$. Then $S T$ has a unique fixed point $z$ in $X$ and $T S$ has a unique fixed point $w$ in $Y$. Further, $T z=w$ and $S w=z$.

Theorem 1.2. (Fisher) [2] Let $(X, d)$ and $(Y, \rho)$ be complete metric spaces, let $T$ be a continuous mapping of $X$ into $Y$ and let $S$ be a mapping of $Y$ into $X$ satisfying the inequalities

$$
\begin{aligned}
d\left(S T x, S T x^{\prime}\right) & \leq c \max \left\{d\left(x, x^{\prime}\right), d(x, S T x), d\left(x^{\prime}, S T x^{\prime}\right), \rho\left(T x, T x^{\prime}\right)\right\} \\
\rho\left(T S y, T S y^{\prime}\right) & \leq c \max \left\{\rho\left(y, y^{\prime}\right), \rho(y, S T y), \rho\left(y^{\prime}, S T y^{\prime}\right), d\left(S y, S y^{\prime}\right)\right\}
\end{aligned}
$$

for all $x, x^{\prime}$ in $X$ and $y, y^{\prime}$ in $Y$, where $0 \leq c<1$. Then $S T$ has a unique fixed point $z$ in $X$ and $T S$ has a unique fixed point $w$ in $Y$. Further, $T z=w$ and $S w=z$.

Nung N. P. [3] generalized theorem 1.1 with three mappings in three complete metric spaces by taking all three mappings continuous. R. K. Jain [4] also generalized theorem 1.2 with three mappings in three complete metric spaces considering two of the mappings continuous. R. K. Jain, H. K. Sahu and Brian Fisher [5] generalized theorem 1.2 with three mappings in three complete metric spaces. Out of the three mappings they take two mappings to be continuous. R.K. Jain, A. K. Shrivastava and Brian Fisher [6] generalized theorem 1.1 to three mappings, taking product (square) in three complete metric spaces with one continuous mapping. Brain Fisher and P. P. Murthy [7] generalized theorem 1.2 with two pairs of mapping in two complete metric spaces with one of the mapping continuous.

Fisher B., R. K. Namdeo, N. K. Tiwari and Kenan Tas [8] proved the following related fixed point theorem. 
Theorem 1.3. Let $(X, d)$ and $(Y, \rho)$ be complete metric spaces. Let $T$ be a mapping of $X$ into $Y$ and let $S$ be a mapping of $Y$ into $X$ satisfying the inequalities

$$
\begin{aligned}
d\left(S y, S y^{\prime}\right) d\left(S T x, S T x^{\prime}\right) \leq & c \max \left\{d\left(S y, S y^{\prime}\right) \rho\left(T x, T x^{\prime}\right), d\left(x^{\prime}, S y\right) \rho\left(y^{\prime}, T x\right),\right. \\
& \left.d\left(x, x^{\prime}\right) d\left(S y, S y^{\prime}\right), d(S y, S T x) d\left(S y^{\prime}, S T x^{\prime}\right)\right\} \\
\left.\rho\left(T x, T x^{\prime}\right) \rho\left(T S y, T S y^{\prime}\right)\right\} \leq & c \max \left\{d\left(S y, S y^{\prime}\right) \rho\left(T x, T x^{\prime}\right), d\left(x^{\prime}, S y\right) \rho\left(y^{\prime}, T x\right),\right. \\
& \left.\rho\left(y, y^{\prime}\right) d\left(T x, T x^{\prime}\right), \rho(T x, T S y) \rho\left(T x^{\prime}, T S y^{\prime}\right)\right\}
\end{aligned}
$$

for all $x, x^{\prime}$ in $X$ and $y, y^{\prime}$ in $Y$, where $0 \leq c<1$. If either $T$ or $S$ is continuous then $S T$ has a unique fixed point $z$ in $X$ and $T S$ has a unique fixed point $\omega$ in $Y$. Further, $T z=\omega$ and $S \omega=z$.

M. Ranjit and Y. Rohen [9] generalized theorem 1.3 by considering two pairs of mappings in two complete metric spaces with one of the mapping continuous. Y. Rohen [10] generalized theorem 1.3 to set valued mappings. Y. Rohen [11] generalized the results of [7] by considering two pairs of set valued mappings.

Brain Fisher and Duran Turkoghu [12] generalized theorem 1.2 to set valued mappings. This is the first result in set valued mappings. They proved the following theorem.

Theorem 1.4. Let $\left(X, d_{1}\right)$ and $\left(Y, d_{2}\right)$ be complete metric spaces, let $F$ be mapping of $X$ into $B(Y)$ and $G$ be mapping of $Y$ into $B(X)$ satisfying the inequalities

$$
\begin{aligned}
& \delta_{1}\left(G F x, G F x^{\prime}\right) \leq c \max \left\{d_{1}\left(x, x^{\prime}\right), \delta_{1}(x, G F x), \delta_{1}\left(x^{\prime}, G F x^{\prime}\right), \delta_{2}\left(F x, F x^{\prime}\right)\right\} \\
& \delta_{2}\left(F G y, F G y^{\prime}\right) \leq c \max \left\{d_{2}\left(y, y^{\prime}\right), \delta_{2}(y, F G y), \delta_{2}\left(y^{\prime}, F G y^{\prime}\right), \delta_{1}\left(G y, G y^{\prime}\right)\right\}
\end{aligned}
$$

For all $x, x^{\prime}$ in $X$ and $y, y^{\prime}$ in $Y$, where $0 \leq c<1$. If $F$ is continuous, then $G F$ has a unique fixed point $z$ in $X$ and $F G$ has a unique fixed point $w$ in $Y$.

Sarika Jain and Brain Fisher [13] generalized theorem 1.4 by using three set valued mappings in three complete metric spaces. Out of the three mappings they take two mappings continuous. R. K. Namdeo and Brian Fisher [14] generalized theorem 1.4 by considering two pairs of mappings in two complete metric spaces considering one of the mapping continuous. V. K. Chourasia and Brian Fisher [15] generalized theorem 1.4 to two pairs of set valued mappings.

Abdelkrim Aliouche and Brian Fisher [16] proved the following theorem which uses rational inequalities. 
Theorem 1.5. Let $(X, d)$ and $(Y, \rho)$ be complete metric spaces. Let $A, B$ be mappings of $X$ into $Y$ and let $S, T$ be mappings of $Y$ into $X$ satisfying the inequalities

$$
\begin{aligned}
\rho\left(B S y, A T y^{\prime \prime}\right) & \leq c \frac{f\left(x, x^{\prime \prime}, y, y^{\prime \prime}\right)}{h\left(x, x^{\prime \prime}, y, y^{\prime \prime}\right)} \\
d\left(S A x, T B x^{\prime \prime}\right) & \leq c \frac{g\left(x, x^{\prime \prime}, y, y^{\prime \prime}\right)}{h\left(x, x^{\prime \prime}, y, y^{\prime \prime}\right)}
\end{aligned}
$$

for all $x, x^{\prime}$ in $X$ and $y, y^{\prime}$ in $Y$ for which $h\left(x, x^{\prime \prime}, y, y^{\prime \prime}\right) \neq 0$, where

$$
\begin{aligned}
f\left(x, x^{\prime \prime}, y, y^{\prime \prime}\right)= & \max \left\{d\left(x, x^{\prime \prime}\right) \rho\left(y, y^{\prime \prime}\right), d(x, S y) d\left(x^{\prime \prime}, T y^{\prime \prime}\right), d\left(x, T y^{\prime \prime}\right) d\left(x^{\prime \prime}, S y\right),\right. \\
& \left.\rho\left(y, B y^{\prime \prime}\right) \rho\left(y^{\prime \prime}, A x\right)\right\} \\
g\left(x, x^{\prime \prime}, y, y^{\prime \prime}\right)= & \max \left\{\rho\left(A x, B x^{\prime \prime}\right) d\left(S y, T y^{\prime \prime}\right), \rho(A x, B S y) \rho\left(B x^{\prime \prime}, A T y^{\prime \prime}\right),\right. \\
& \left.\rho\left(A x, A T y^{\prime \prime}\right) \rho\left(B x^{\prime \prime}, B S y\right), d\left(S x, T B x^{\prime \prime}\right) d\left(T y^{\prime \prime}, S A x\right)\right\} \\
h\left(x, x^{\prime \prime}, y, y^{\prime \prime}\right)= & \max \left\{\rho\left(A x, B x^{\prime \prime}\right), d\left(S A x, T B x^{\prime \prime}\right), d\left(S y, T y^{\prime \prime}\right), \rho\left(B S y, A T y^{\prime \prime}\right)\right\}
\end{aligned}
$$

and $0 \leq c<1$. If one of the mappings $A, B, S$ and $T$ is continuous, then $S A$ and $T B$ have a unique common fixed point $z$ in $X$ and $B S$ and $A T$ have a unique common fixed $w$ in $Y$. Further, $A z=B z=w$ and $S w=T w=z$.

Abdelkrim Aliouche and Brian Fisher [17] proved a theorem similar to theorem 1.5 without using the continuity of mappings. R. K. Namdeo and Brian Fisher [18] proved another version of theorem 1.5 with different inequalities. R. K. Namdeo and Brian Fisher [19] generalized theorem 1.5 by considering three pairs of mappings in three complete metric spaces with the condition that two of the mappings are continuous. R. K. Namdeo and Brian Fisher [20] generalized theorem 1.5 by considering three pairs of mappings in three complete metric spaces. They also put the condition that two of the mappings must be continuous.

R.K. Jain, H. K. Sahu and Brain Fisher [21] proved the following theorem.

Theorem 1.6. Let $(X, d),(Y, \rho)$ and $(Z, \sigma)$ be complete metric spaces and suppose $T$ is a mapping of $X$ into $Y, S$ is a mapping of $Y$ into $Z$ and $R$ is a mapping of $Z$ into $X$ satisfying the inequalities

$$
d(R S y, R S T x) \leq c \frac{f_{1}(x, y)}{g_{1}(x, y)}
$$




$$
\begin{aligned}
\rho(T R z, T R S y) & \leq c \frac{f_{2}(y, z)}{g_{2}(y, z)} \\
\sigma(S T x, S T R z) & \leq c \frac{f_{3}(z, x)}{g_{3}(z, x)}
\end{aligned}
$$

for all $x$ in $X, y$ in $Y$ for which

$$
g_{1}(x, y) \neq 0, g_{2}(y, z) \neq 0, g_{3}(z, x) \neq 0,
$$

where $0 \leq c<1$ and

$$
\begin{aligned}
f_{1}(x, y)= & \max \{d(x, R S T x) \sigma(S y, S T x), d(x, R S T x) \rho(y, T R S y), \\
& d(x, R S y) \rho(y, T x)\}, \\
f_{2}(y, z)= & \max \{\rho(y, T R S y) d(R z, R S y), \rho(y, T R S y) \sigma(z, S T R z), \\
& \rho(y, T R z) \sigma(z, S y)\}, \\
f_{3}(z, x)= & \max \{\sigma(z, S T R z) \rho(T x, T R z), \sigma(z, S T R z) d(x, R S T x), \\
& \sigma(z, S T x) d(x, R z)\}, \\
g_{1}(x, y)= & \max \{d(x, R S y), d(x, R S T x), \rho(T x, T R S y)\}, \\
g_{2}(y, z)= & \max \{\rho(y, T R z), \rho(y, T R S y), d(S y, S T R z)\}, \\
g_{3}(z, x)= & \max \{\sigma(z, S T x), \sigma(z, S T R z), d(R z, R S T x)\} .
\end{aligned}
$$

Then $R S T$ has a unique fixed point $u$ in $X, T R S$ has a unique fixed point $v$ in $Y$ and $S T R$ has a unique fixed point $w$ in $Z$. Further, $T u=v, S v=w$ and $R w=u$.

Luljeta Kakina and Kristaq [22] generalized theorem 1.6 by considering four pairs of mappings in four complete metric spaces. Here mappings are not continuous. A.K. Chaubey, M.D. Gupta and D.P. Sahu [23] generalized theorem 1.6 by considering five pairs of mappings in five complete metric spaces. In this case the continuity of mappings is not necessary. Luljeta Kakina [24] proved a related fixed point theorem in three complete metric spaces with new inequalities. In this case mappings need not be continuous.

Sampada Navshinde, J. Achari and Brian Fisher [25] proved the following theorem.

Theorem 1.7. Let $(X, d),(Y, \rho)$ and $(Z, \sigma)$ be complete metric spaces. If $T$ is continuous mapping of $X$ into $Y, S$ is a mapping of $Y$ into $Z$ and $R$ is a mapping of $Z$ into $X$ satisfying the inequalities

$$
d\left(R S T x, R S T x^{\prime}\right) \leq c \max \left\{\frac{d\left(x, x^{\prime}\right)\{1+d(x, R S T x)\}}{1+d\left(x, x^{\prime}\right)}\right.
$$




$$
\begin{aligned}
& \frac{d\left(x^{\prime}, R S T x\right)\{1+d(x, R S T x)\}}{1+d\left(x, x^{\prime}\right)}, \\
& \frac{d\left(x^{\prime}, R S T x^{\prime}\right)\{1+d(x, R S T x)\}}{1+d\left(x, x^{\prime}\right)} \text {, } \\
& \left.\rho\left(T x, T x^{\prime}\right), \sigma\left(S T x, S T x^{\prime}\right)\right\} \\
& \rho\left(T R S y, T R S y^{\prime}\right) \leq c \max \left\{\frac{\rho\left(y, y^{\prime}\right)\{1+\rho(y, T R S y)\}}{1+\rho\left(y, y^{\prime}\right)}\right. \\
& \frac{\rho\left(y^{\prime}, T R S y\right)\left\{1+\rho\left(y, T R S y^{\prime}\right)\right\}}{1+\rho\left(y, y^{\prime}\right)}, \\
& \frac{\rho\left(y^{\prime}, T R S y^{\prime}\right)\{1+\rho(y, T R S y)\}}{1+\rho\left(y, y^{\prime}\right)}, \\
& \left.\sigma\left(S y, S y^{\prime}\right), d\left(R S y, R S y^{\prime}\right)\right\} \\
& \sigma\left(S T R z, S T R z^{\prime}\right)=c \max \left\{\frac{\sigma\left(z, z^{\prime}\right)\{1+\sigma(z, S T R z)\}}{1+\sigma\left(z, z^{\prime}\right)},\right. \\
& \frac{\sigma\left(z^{\prime}, S T R z\right)\left\{1+\sigma\left(z, S T R z^{\prime}\right)\right\}}{1+\sigma\left(z, z^{\prime}\right)}, \\
& \frac{\sigma\left(z^{\prime}, S T R z^{\prime}\right)\{1+\sigma(z, S T R z)\}}{1+\sigma\left(z, z^{\prime}\right)}, \\
& \left.d\left(R z, R z^{\prime}\right), \rho\left(T R z, T R z^{\prime}\right)\right\}
\end{aligned}
$$

for all $x, x^{\prime}$ in $X, y, y^{\prime}$ in $Y$ and $z, z^{\prime}$ in $Z$, where $0 \leq c<1$, then $R S T$ has a unique fixed point $u$ in $X$. TRS has a unique fixed point $v$ in $Y$ and $S T R$ has a unique fixed point $w$ in $Z$. Further, $T u=v, S v=w$ and $R w=u$.

Taieb Hamaizia and Abdelkrim Aliouche [26] proved a theorem which is one of the theorem proved by Ranjit and Rohen [9] in 1999. Vishal Gupta [27] generalized the result of Jain, Sahu and Fisher [5] by taking four mappings in four complete metric spaces. Out of the four mappings three mappings are continuous. 
R. K. Saini, Seema Devi and Naveen Gulati [28] proved the following theorem:

Theorem 1.8. Let $(X, d)$ and $(Y, \rho)$ be complete metric spaces. If $T$ : $X \rightarrow Y$ and $S: Y \rightarrow X$ satisfying the inequalities,

$$
\begin{aligned}
\rho^{3}(T x, T S y) \leq & c_{1} \max \{\rho(y, T x) d(x, S y) \rho(y, T x), \rho(y, T x) \rho(y, T x) \rho(y, T S y), \\
& \rho(y, T S y) d(x, S y) \rho(y, T S y)\} \\
d^{3}(S y, S T x) \leq & c_{2} \max \{d(x, S y) \rho(y, T x) d(x, S y), d(x, S y) d(x, S y) d(x, S T x), \\
& \rho(y, T x) d(x, S T x) d(x, S T x)\}
\end{aligned}
$$

$\forall x \in X$ and $y \in Y$ where $0 \leq c_{1}, c_{2}<1$ then $S T$ has a unique fixed point $z \in X$ and $T S$ has a unique fixed point $w \in Y$. Further, $T z=w$, and $S w=z$.

Karim Chaira, El-Miloudi Marhrani [29] proved the following theorem.

Theorem 1.9. Let $(X, d)$ and $(Y, \delta)$ be two metric spaces; we assume that $(X, d)$ is complete. Let $T: X \rightarrow Y$ and $S: Y \rightarrow X$ be two mappings such that

$$
\begin{aligned}
& d(S y, S T x) \leq \alpha(\delta(y, T x)) \max \{d(x, S y), \delta(y, T x)\}+\beta(\delta(y, T x)) d(x, S T x) \\
& \delta(T x, T S y) \leq \alpha(\delta(x, S y)) \max \{d(x, S y), \delta(y, T x)\}+\beta(\delta(x, S y)) \delta(y, T S y)
\end{aligned}
$$

where $\alpha, \beta:[0, \infty[$ are two functions satisfying:

$$
\lim _{t \rightarrow t_{0}^{+}} \sup (\alpha(t)+\beta(t))<1, t_{0} \in[0, \infty[
$$

Then there exists a unique pair $\left(x^{*}, y^{*}\right) \in X \times Y$ such that $T x^{*}=y^{*}$ and $S y^{*}=x^{*}$ then $S T x^{*}=x^{*}$ and TS $y^{*}=y^{*}$.

Ismat Beg and Sunny Chauhan [30] proved the following theorem as the first related fixed point theorem in menger space. They used set valued mappings.

Theorem 1.10. Let $(X, F, \triangle),(Y, G, \triangle)$ and $(Z, H, \triangle)$ be three complete Menger spaces, where $\triangle$ is a continuous t-norm. If $P$ is a continuous mapping of $X$ into $C B(Y), Q$ is a continuous mapping of $Y$ into $C B(Z)$, and $R$ is a mapping of $Z$ into $C B(X)$ satisfying the inequalities

$$
{ }_{\delta} F_{R Q P x, R Q P x^{\prime}}(k t) \geq \min \left\{F_{x, x^{\prime}}(t),{ }_{\delta} F_{x, R Q P x}(t),{ }_{\delta} F_{x^{\prime}, R Q P x^{\prime}}(t),\right.
$$




$$
\begin{aligned}
& \left.{ }_{\delta} G_{P x, P x^{\prime}}(t),_{\delta} H_{Q P x, Q P x^{\prime}}(t)\right\}, \\
{ }_{\delta} G_{P R Q y, P R Q y^{\prime}}(k t) \geq & \min \left\{G_{y, y^{\prime}}(t),_{\delta} G_{y, P R Q y}(t),{ }_{\delta} G_{y^{\prime}, P R Q y^{\prime}}(t),\right. \\
& \left.{ }_{\delta} H_{Q y, Q y^{\prime}}(t),_{\delta} F_{R Q y, R Q y^{\prime}}(t)\right\}, \\
{ }_{\delta} H_{Q P R z, Q P R z^{\prime}}(k t) \geq & \min \left\{H_{z, z^{\prime}}(t),_{\delta} H_{z, Q P R z}(t){ }_{\delta} H_{z^{\prime}, Q P R z^{\prime}}(t),\right. \\
& \left.{ }_{\delta} F_{R z, R z^{\prime}}(t){ }_{,} G_{P R z, P R z^{\prime}}(t)\right\}
\end{aligned}
$$

for all $x, x^{\prime} \in X, y, y^{\prime} \in Y$ and $z, z^{\prime} \in Z, k \in(0,1)$ and $t>0$. Then $R Q P$ has a unique fixed point $u$ in $X, P R Q$ has a unique fixed point $v$ in $Y$ and $Q P R$ has a unique fixed point $w$ in $Z$. Further $P u=\{v\}, Q v=\{w\}$ and $R w=\{u\}$.

Sunny Chauhan, Ismat Beg and B. D. Pant [31] proved a related fixed point theorem in two menger spaces by using two pairs of single valued mappings. Out of the four mappings they consider one to be continuous. R. C. Dimri and M. Sharma [32] generalized theorem 1.10 to three pairs of set valued mappings.

D. Turkoglu and B. Fisher [33] proved the first related fixed point theorem in uniform space by extending theorem 1.2.

Theorem 1.11. Let $\left(X, U_{1}\right)$ and $\left(Y, U_{2}\right)$ be complete Hausdroff uniform spaces defined by $\left\{d_{1}^{i}, i \in I\right\}=P_{1}^{*},\left\{d_{2}^{i}, i \in I\right\}=P_{2}^{*}$ and $,\left(2^{X}, U_{1}^{*}\right),\left(2^{Y}, U_{2}^{*}\right)$ hyperspaces, let $F$ is a mapping of $X$ into $2^{Y}$ and $G$ is a mapping of $Y$ into $2^{X}$ satisfying the inequalities

$$
\begin{aligned}
\delta_{1}^{i}\left(G F x, G F x^{\prime}\right) & \leq c_{i} \max \left\{d_{1}^{i}\left(x, x^{\prime}\right), d_{1}^{i}(x, G F x), \delta_{1}^{i}\left(x^{\prime}, G F x^{\prime}\right), \delta_{2}^{i}\left(F x, F x^{\prime}\right)\right\} \\
\delta_{2}^{i}\left(F G y, F G y^{\prime}\right) & \leq c_{i} \max \left\{d_{2}^{i}\left(y, y^{\prime}\right), d_{1}^{i}(y, F G y), \delta_{2}^{i}\left(y^{\prime}, F G y^{\prime}\right), \delta_{1}^{i}\left(G y, G y^{\prime}\right)\right\}
\end{aligned}
$$

for all $x, x^{\prime} \in X, y, y^{\prime} \in Y, i \in I$ where $0 \leq c_{i}<1$. If $F$ is continuous then $G F$ has a unique fixed point $z$ in $X$. FG has a unique fixed point $w$ in $Y$. Further, $F z=\{w\}$, and $G w=\{z\}$.

L. Bishwakumar and Y. Rohen [34] generalized the result of Murthy and Fisher [7] to uniform space. Yumnam Rohen and L. Bishwakumar [35] generalized the result of Namdeo, Tiwari, Fisher and Tas [8] to uniform space. L. Ibeni and Yumnam Rohen [36] extended theorem 1.11 to three mappings in three uniform spaces. Y. Rohen, L. Bishwakumar and B. Fisher [37] extended the result of Ranjit and Rohen [9] to uniform space.

Valeriu Popa, [38] proved the following theorem. 
Theorem 1.12. Let $(X, d)$ and $(Y, e)$ be complete metric spaces. If $T$ is a mapping of $X$ into $Y$ and $S$ is a mapping of $Y$ into $X$ satisfying the inequalities $e^{2}(T x, T S y) \leq c_{1} \max \{d(x, S y) e(y, T x), d(x, S y) e(y, T S y), e(y, T x), e(y, T S y)\}$ $d^{2}(S y, S T x) \leq c_{2} \max \{e(y, T x) d(x, S y), e(y, T x) d(x, S T x), d(x, S y), d(x, S T x)\}$

For all $x$ in $X$ and $y$ in $Y$, where $0 \leq c_{1}, c_{2}<1$, then $S T$ has a unique fixed point $z$ in $X$ and $T S$ has a unique fixed point $w$ in $Y$. Further, $T z=w$ and $S w=z$.

Y. J. Cho, S. M. Kang and S. S. Kim [39] proved theorem 1.12 by using implicit relation. Some other results of Popa [38, 40, 41] also extended as corollaries. Valeriu Popa [40] generalized the result of Nung [3] with the mappings satisfying three implicit relations on three complete metric spaces. Valeriu Popa [41] generalized the result of Fisher and Murthy [7] for two pairs of mappings on two metric spaces satisfying an implicit relation. Y. Rohen and L. Bishwakumar [42] generalized the result of Jain, Sahu and Fisher [5] to three mappings satisfying implicit relations. Luljeta Kakina and Kristaq Kakina [43] proved a new related fixed point theorem in two complete metric spaces satisfying implicit relation. Kristaq Kakina and Luljeta Kakina [44] proved a new related fixed point theorem in three complete metric spaces satisfying implicit relation. Luljeta Gjoni and Kristaq Kakina, [45] proved a related fixed point theorem for four mappings in four metric spaces using an implicit relation. Abdelkrim Aliouche, Faical Merghadi and Brian Fisher [46] proved two related fixed point theorems for mappings satisfying implicit relations of integral type in two complete and compact metric spaces. Faycal Merghadi, Abdelkrim Aliouche and Brian Fisher [47] proved a related fixed point theorem for $n$ mappings in $n$ complete metric spaces satisfying implicit relation.

B. Fisher and K. P. R. Rao [48] proved a related fixed point theorem for three mappings without using the continuity of the mappings. They take three metric spaces of which one is a compact metric space. L. Bishwakumar and Y. Rohen [49] proved another version of the theorem of Fisher and Rao [48] by taking different inequality. Zaheer K. Ansari, Manish Sharma and Arun Garg [50] proved two related fixed point theorems in three complete metric spaces by considering three continuous mappings. Rajesh Shrivastava, Kiran Rathore and K. Qureshi [51] proved a result similar to Fisher and Rao [48].

M. Aamri, A. Bassou, S. Bennani and D. El Moutawakil [52] proved following theorem in symmetric space.

Theorem 1.13. Let $(X, d)$ be a symmetric space and $(Y, \delta)$ be a complete metric space, let $T$ be a mapping of $X$ into $Y$, and let $S$ be a mapping of $Y$ 
into $X$ such that

$$
\begin{aligned}
& \delta(T x, T S y) \leq c \max \{d(x, S y), \delta(y, T x), \delta(y, T S y)\} \\
& d(S y, S T x) \leq c \max \{\delta(y, T x), d(x, S y), d(x, S T x)\},
\end{aligned}
$$

for all $x \in X$ and $y \in Y$ where $0 \leq c<1$. Then $S T$ has a unique fixed point $z \in X$ and $T S$ has a unique fixed point $w \in Y$ such that $T z=w$ and $S w=z$.

M. Aamri,A. Bassou, S. Bennani and D. El Moutawakil [53] proved the following related fixed point theorem in symmetric spaces.

Theorem 1.14. Let $(X, d)$ and $(Y, \delta)$ be two 1-continuous semi-metric spaces. Let $A, B$ be mappings of $X$ into $Y$, and let $S, T$ be mappings of $Y$ into $X$ satisfying

$$
\begin{aligned}
d\left(S A x, T B x^{\prime}\right) & \leq c \max \left\{d\left(x, x^{\prime}\right), d(x, S A x), d\left(x^{\prime}, T B x^{\prime}\right), \delta\left(A x, B x^{\prime}\right)\right\} \\
\delta\left(B S y, A T y^{\prime}\right) & \leq c \max \left\{\delta\left(y, y^{\prime}\right), \delta(y, B S y), \delta\left(y^{\prime}, A T y^{\prime}\right), d\left(S y, T y^{\prime}\right)\right\}
\end{aligned}
$$

for all $x, x^{\prime}$ in $X$ and $y, y^{\prime}$ in $Y$, where $0 \leq c<1$.

If either $X$ is $\left(\sum\right) d$-complete and $Y$ satisfies $\left(W_{4}\right)$ or $Y$ is $\left(\sum\right) d$-complete and $X$ satisfies $\left(W_{4}\right)$, and one of the mappings $A, B, S$ and $T$ is continuous then $S A$ and $T B$ have a unique common fixed point $z$ in $X$ and $B S$ and $A T$ have a unique common fixed point $w$ in $Y$. Further, $A z=B z=w$ and $S w=T w=z$.

Note: For condition $\left(W_{4}\right)$ see [53].

Sushil Sharma, Bhavma Deshpande and Deepti Thakur [54] proved the following theorem in Fuzzy metric spaces.

Theorem 1.15. Let $\left(X, M_{1}, N_{1}, *, \diamond\right)$ and $\left(Y, M_{2}, N_{2}, *, \diamond\right)$ be two complete intuitionistic fuzzy metric spaces. Let $A, B$ be mappings from $X$ into $Y$ and let $S, T$ be mappings from $Y$ into $X$ satisfying the inequalities:

$$
\begin{aligned}
M_{1}\left(S A x, T B x^{\prime}, k t\right) \geq & M_{1}\left(x, x^{\prime}, t\right) * M_{1}(x, S A x, t) \\
& * M_{1}\left(x^{\prime}, T B x^{\prime}, t\right) * M_{1}\left(S A x, T B x^{\prime}, t\right) \\
\text { and } N_{1}\left(S A x, T B x^{\prime}, k t\right) \leq & N_{1}\left(x, x^{\prime}, t\right) \diamond N_{1}(x, S A x, t) \\
& \diamond N_{1}\left(x^{\prime}, T B x^{\prime}, t\right) \diamond N_{1}\left(S A x, T B x^{\prime}, t\right) \\
M_{2}\left(B S y, A T y^{\prime}, k t\right) \geq & M_{2}\left(y, y^{\prime}, t\right) * M_{2}(y, B S y, t) \\
& * M_{2}\left(y^{\prime}, A T y^{\prime}, t\right) * M_{2}\left(B S y, A T y^{\prime}, t\right) \\
\text { and } N_{2}\left(B S y, A T y^{\prime}, k t\right) \leq & N_{2}\left(y, y^{\prime}, t\right) \diamond N_{2}(y, B S y, t)
\end{aligned}
$$




$$
\diamond N_{2}\left(y^{\prime}, A T y^{\prime}, t\right) \diamond N_{2}\left(B S y, A T y^{\prime}, t\right) .
$$

for all $x, x^{\prime}$ in $X$ and $y, y^{\prime}$ in $Y$. If one of the mappings $A, B, S, T$ is continuous, then $S A$ and $T B$ have a unique common fixed point $z$ in $X$ and $B S$ and $A T$ have a unique common fixed point $w$ in $Y$. Further, $A z=B z=w$ and $S w=T w=z$.

Sushil Sharma, Prashant Tilwankar [55] generalized theorem 1.15 by taking six mappings in three complete fuzzy metric spaces. Sandeep Bhatt, Pankajkumar Mishra and Shruti Chaukiyal [56] proved a related fixed point theorem of three mappings on three complete fuzzy metric spaces. Out of the three mappings they consider two mappings to be continuous. T. K. Samanta, Sumit Mohinta and Iqbal H. Jebril [57] proved a related fixed point theorem for two pairs of mappings in two fuzzy metric spaces. Faycel Merghadi and Abdelkrim Aliouche [58] proved a related fixed point theorem in three instituitionistic fuzzy metric spaces using an implicit relation.

\section{Main Result}

We now prove the following related fixed point theorem which improves Theorem 1.7 .

Theorem 2.1. Let $\left(X, d_{1}\right),\left(Y, d_{2}\right)$ and $\left(Z, d_{3}\right)$ be complete metric spaces. Let $T$ be a mapping from $X$ into $B(Y), S$ be a mapping from $Y$ into $B(Z)$ and $R$ be a mapping from $Z$ into $B(X)$ satisfying the inequalities

$$
\begin{aligned}
\delta_{1}\left(R S T x, R S T x^{\prime}\right) \leq & c \max \left\{\frac{d_{1}\left(x, x^{\prime}\right)\left\{1+\delta_{1}(x, R S T x)\right\}}{1+d_{1}\left(x, x^{\prime}\right)},\right. \\
& \frac{\delta_{1}\left(x^{\prime}, R S T x\right)\left\{1+\delta_{1}\left(x, R S T x^{\prime}\right)\right\}}{1+d_{1}\left(x, x^{\prime}\right)}, \\
& \frac{\delta_{1}\left(x^{\prime}, R S T x^{\prime}\right)\left\{1+\delta_{1}(x, R S T x)\right\}}{1+d_{1}\left(x, x^{\prime}\right)}, \\
& \left.\delta_{2}\left(T x, T x^{\prime}\right), \delta_{3}\left(S T x, S T x^{\prime}\right)\right\} \\
\delta_{3}\left(T R S y, T R S y^{\prime}\right) \leq & c \max \left\{\frac{d_{2}\left(y, y^{\prime}\right)\left\{1+\delta_{2}(y, T R S y)\right\}}{1+d_{2}\left(y, y^{\prime}\right)},\right.
\end{aligned}
$$




$$
\begin{aligned}
& \frac{\delta_{2}\left(y^{\prime}, T R S y\right)\left\{1+\delta_{2}\left(y, T R S y^{\prime}\right)\right\}}{1+d_{2}\left(y, y^{\prime}\right)}, \\
& \frac{\delta_{2}\left(y^{\prime}, T R S y^{\prime}\right)\left\{1+\delta_{2}(y, T R S y)\right\}}{1+d_{2}\left(y, y^{\prime}\right)}, \\
& \left.\delta_{2}\left(S y, S y^{\prime}\right), \delta_{3}\left(R S y, R S y^{\prime}\right)\right\} \\
\delta_{3}\left(S T R z, S T R z^{\prime}\right) \leq & c \max \left\{\frac{d_{3}\left(z, z^{\prime}\right)\left\{1+\delta_{3}(z, S T R z)\right\}}{1+d_{3}\left(z, z^{\prime}\right)},\right. \\
& \frac{\delta_{3}\left(z^{\prime}, S T R z\right)\left\{1+\delta_{3}\left(z, S T R z^{\prime}\right)\right\}}{1+d_{3}\left(z, z^{\prime}\right)}, \\
& \frac{\delta_{3}\left(z^{\prime}, S T R z^{\prime}\right)\left\{1+\delta_{3}(z, S T R z)\right\}}{1+d_{3}\left(z, z^{\prime}\right)}, \\
& \left.\delta_{1}\left(R z, R z^{\prime}\right), \delta_{2}\left(T R z, T R z^{\prime}\right)\right\}
\end{aligned}
$$

for all $x, x^{\prime}$ in $X, y, y^{\prime}$ in $Y$ and $z, z^{\prime}$ in $Z$, where $0 \leq c<1$, if $S$ and $T$ are continuous then $R S T$ has a unique fixed point $u$ in $X, T R S$ has a unique fixed point $v$ in $Y$ and $S T R$ has a unique fixed point $w$ in $Z$.

Proof. Let $x=x_{0}$ be an arbitrary point in $X$. Define sequences $\left\{x_{n}\right\}$ in $X$, $\left\{y_{n}\right\}$ in $Y$ and $\left\{z_{n}\right\}$ in $Z$ inductively by $x_{n}=R z_{n}, y_{n}=T x_{n-1}, z_{n}=S y_{n}$ for $n=1,2, \ldots$.

Applying inequality (2.2), we have

$$
\begin{aligned}
d_{2}\left(y_{n}, y_{n+1}\right)= & \delta_{2}\left(T R S y_{n-1}, T R S y_{n}\right) \\
\leq & c \max \left\{\frac{d_{2}\left(y_{n-1}, y_{n}\right)\left\{1+\delta_{2}\left(y_{n-1}, T R S y_{n-1}\right)\right\}}{1+d_{2}\left(y_{n-1}, y_{n}\right)},\right. \\
& \left.\left.\frac{\delta_{2}\left(y_{n}, T R S y_{n-1}\right)\left\{1+\delta_{2}\left(y_{n-1}, T R S y_{n}\right)\right\}}{1+d_{2}\left(y_{n-1}, y_{n}\right)}, T R y_{n-1}\right)\right\} \\
& \frac{\delta_{2}\left(y_{n}, T R S y_{n}\right)\left\{1+\delta_{2}\left(y_{n-1}, T R d_{2}\left(y_{n-1}, y_{n}\right)\right.\right.}{\left.\left.1+d_{n-1}, R S y_{n}\right)\right\}} \\
& \left.\delta_{3}\left(S y_{n-1}, S y_{n}\right), \delta_{1}\left(R S y_{n-1}\right), d_{3}\left(z_{n-1}, z_{n}\right)\right\} \\
\leq & c \max \left\{d_{1}\left(x_{n-1}, x_{n}\right), d_{2}\left(y_{n-1}, y_{n}\right),\right.
\end{aligned}
$$


Using inequality (2.3), we have

$$
\begin{aligned}
d_{3}\left(z_{n}, z_{n+1}\right)= & \delta_{3}\left(S T R z_{n-1}, S T R z_{n}\right) \\
\leq & c \max \left\{\frac{d_{3}\left(z_{n-1}, z_{n}\right)\left\{1+\delta_{3}\left(z_{n-1}, S T R z_{n-1}\right)\right\}}{1+d_{3}\left(z_{n-1}, z_{n}\right)}\right. \\
& \frac{\delta_{3}\left(z_{n}, S T R z_{n-1}\right)\left\{1+\delta_{3}\left(z_{n-1}, S T R z_{n}\right)\right\}}{1+d_{3}\left(z_{n-1}, z_{n}\right)}, \\
& \frac{\delta_{3}\left(z_{n}, S T R z_{n}\right)\left\{1+\delta_{3}\left(z_{n-1}, S T R z_{n-1}\right)\right\}}{1+d_{3}\left(z_{n-1}, z_{n}\right)} \\
& \left.\delta_{1}\left(R z_{n-1}, R z_{n}\right), \delta_{2}\left(T S z_{n-1}, T R z_{n}\right)\right\} \\
\leq & c \max \left\{d_{1}\left(x_{n-1}, x_{n}\right), d_{2}\left(y_{n-1}, y_{n}\right), d_{3}\left(z_{n-1}, z_{n}\right)\right\}
\end{aligned}
$$

on using inequality (2.4).

Using inequality (2.1), we have

$$
\begin{aligned}
d_{1}\left(x_{n}, x_{n+1}\right)= & \delta_{1}\left(R S T x_{n-1}, R S T x_{n}\right) \\
\leq & c \max \left\{\frac{d_{1}\left(x_{n-1}, x_{n}\right)\left\{1+\delta_{1}\left(x_{n-1}, R S T x_{n-1}\right)\right\}}{1+d_{1}\left(x_{n-1}, x_{n}\right)},\right. \\
& \frac{\delta_{1}\left(x_{n}, R S T x_{n-1}\right)\left\{1+\delta_{1}\left(x_{n-1}, R S T x_{n}\right)\right\}}{1+d_{1}\left(x_{n-1}, x_{n}\right)}, \\
& \frac{\delta_{1}\left(x_{n}, R S T x_{n}\right)\left\{1+\delta_{1}\left(x_{n-1}, R S T x_{n-1}\right)\right\}}{1+d_{1}\left(x_{n-1}, x_{n}\right)}, \\
& \left.\delta_{2}\left(T x_{n-1}, T x_{n}\right), \delta_{3}\left(S T x_{n-1}, S T x_{n}\right)\right\} \\
\leq & c \max \left\{d_{1}\left(x_{n-1}, x_{n}\right), d_{2}\left(y_{n-1}, y_{n}\right), d_{3}\left(z_{n-1}, z_{n}\right)\right\}
\end{aligned}
$$

on using inequalities (2.4) and (2.5).

It follows easily by induction on using inequalities $(2.4),(2.5)$ and (2.6) that

$$
\begin{aligned}
d_{1}\left(x_{n}, x_{n+1}\right) & \leq c \max \left\{d_{1}\left(x_{1}, x_{2}\right), d_{2}\left(y_{1}, y_{2}\right), d_{3}\left(z_{1}, z_{2}\right)\right\} \\
d_{2}\left(y_{n}, y_{n+1}\right) & \leq c \max \left\{d_{1}\left(x_{1}, x_{2}\right), d_{2}\left(y_{1}, y_{2}\right), d_{3}\left(z_{1}, z_{2}\right)\right\} \\
d_{3}\left(z_{n}, z_{n+1}\right) & \leq c \max \left\{d_{1}\left(x_{1}, x_{2}\right), d_{2}\left(y_{1}, y_{2}\right), d_{3}\left(z_{1}, z_{2}\right)\right\} \\
d_{1}\left(x_{1}, x_{2}\right) & =\delta_{1}\left(R S T x_{0}, R S T x_{1}\right) \\
& \leq c \max \left\{d_{1}\left(x_{0}, x_{1}\right), d_{2}\left(y_{0}, y_{1}\right), d_{3}\left(z_{0}, z_{1}\right)\right\}
\end{aligned}
$$




$$
\begin{aligned}
& d_{1}\left(x_{1}, x_{2}\right) \leq c d_{1}\left(x_{0}, x_{1}\right) \\
& d_{1}\left(x_{1}, x_{2}\right) \leq c^{2} d_{1}\left(x_{0}, x_{1}\right)
\end{aligned}
$$

and so on

$$
\begin{aligned}
& d_{1}\left(x_{n}, x_{n+1}\right) \leq c^{n} d_{1}\left(x_{0}, x_{1}\right) \rightarrow 0 \text { as } 0<c<1 \text { and } n \rightarrow \infty \\
& d_{1}\left(x_{n}, x_{n+p}\right) \leq c^{n+p-1} d_{1}\left(x_{0}, x_{1}\right)
\end{aligned}
$$

Hence $\left\{x_{n}\right\}$ is a Cauchy sequence.

Since $0 \leq c<1$, it follows that $\left\{x_{n}\right\},\left\{y_{n}\right\}$ and $\left\{z_{n}\right\}$ are Cauchy sequences with limits $u, v$ and $w$ in $X, Y$ and $Z$ respectively. Since $T$ and $S$ are continuous, we have

$$
\begin{array}{r}
\lim _{n \rightarrow \infty} y_{n+1}=\lim _{n \rightarrow \infty} T x_{n}=T u=v, \\
\lim _{n \rightarrow \infty} z_{n}=\lim _{n \rightarrow \infty} S y_{n}=S v=w .
\end{array}
$$

Using inequality (2.1) again, we have

$$
\begin{aligned}
\delta_{1}\left(R S T u, x_{n}\right)= & \delta_{1}\left(R S T u, R S T x_{n-1}\right) \\
\leq & c \max \left\{\frac{d_{1}\left(u, x_{n-1}\right)\left\{1+\delta_{1}(u, R S T u)\right\}}{1+d_{1}\left(u, x_{n-1}\right)},\right. \\
& \frac{\delta_{1}\left(x_{n-1}, R S T u\right)\left\{1+\delta_{1}\left(u, R S T x_{n-1}\right)\right\}}{1+d_{1}\left(u, x_{n-1}\right)} \\
& \frac{\delta_{1}\left(x_{n-1}, R S T x_{n-1}\right)\left\{1+\delta_{1}(u, R S T u)\right\}}{1+d_{1}\left(u, x_{n-1}\right)}, \\
& \left.\delta_{2}\left(T u, T x_{n-1}\right), \delta_{3}\left(S T u, S T x_{n-1}\right)\right\} \\
\leq & c \max \left\{\frac{d_{1}\left(u, x_{n-1}\right)\left\{1+\delta_{1}(u, R S T u)\right\}}{1+d_{1}\left(u, x_{n-1}\right)},\right. \\
& \frac{\delta_{1}\left(x_{n-1}, R S T u\right)\left\{1+d_{1}\left(u, x_{n}\right)\right\}}{1+d_{1}\left(u, x_{n-1}\right)} \\
& \frac{d_{1}\left(x_{n-1}, x_{n}\right)\left\{1+\delta_{1}(u, R S T u)\right\}}{1+d_{1}\left(u, x_{n-1}\right)} \\
& \left.\delta_{2}\left(T u, T x_{n-1}\right), \delta_{3}\left(S T u, S T x_{n-1}\right)\right\} .
\end{aligned}
$$

Since $S$ and $T$ are continuous, it follows on letting $n \rightarrow \infty$ that

$$
\delta_{1}(R S T u, u) \leq c \delta_{1}(R S T u, u) .
$$


Thus $R S T u=u$, since $c<1$ and so $u$ is a fixed point of $R S T$. We therefore have $T R S v=T R S T u=T u=v$ and so $S T R w=S T R S v=S v=w$. Hence $v$ and $w$ are fixed points of $T R S$ and $S T R$ respectively.

We now prove the uniqueness of the fixed point $u$. Suppose that $R S T$ has a second fixed point $u^{\prime}$. Then using inequality (1), we have

$$
\begin{aligned}
d_{1}\left(u, u^{\prime}\right)= & \delta_{1}\left(R S T u, R S T u^{\prime}\right) \\
\leq & c \max \left\{\frac{d_{1}\left(u, u^{\prime}\right)\left\{1+\delta_{1}(u, R S T u)\right\}}{1+d_{1}\left(u, u^{\prime}\right)},\right. \\
& \frac{\delta_{1}\left(u^{\prime}, R S T u\right)\left\{1+\delta_{1}\left(u, R S T u^{\prime}\right)\right\}}{1+d_{1}\left(u, u^{\prime}\right)} \\
& \frac{\delta_{1}\left(u^{\prime}, R S T u^{\prime}\right)\left\{1+\delta_{1}(u, R S T u)\right\}}{1+d_{1}\left(u, u^{\prime}\right)} \\
& \left.\delta_{2}\left(T u, T u^{\prime}\right), \delta_{3}\left(S T u, S T u^{\prime}\right)\right\} \\
\leq & c \max \left\{\frac{d_{1}\left(u, u^{\prime}\right)\left\{1+d_{1}(u, u)\right\}}{1+d_{1}\left(u, u^{\prime}\right)},\right. \\
& \frac{d_{1}\left(u^{\prime}, u\right)\left\{1+d_{1}\left(u, u^{\prime}\right)\right\}}{1+d_{1}\left(u, u^{\prime}\right)} \\
& \frac{d_{1}\left(u^{\prime}, u^{\prime}\right)\left\{1+d_{1}(u, u)\right\}}{1+d_{1}\left(u, u^{\prime}\right)}, \\
& \left.\delta_{2}\left(T u, T u^{\prime}\right), \delta_{3}\left(S T u, S T u^{\prime}\right)\right\} \\
= & c \max \left\{\delta_{2}\left(T u, T u^{\prime}\right), \delta_{3}\left(S T u, S T u^{\prime}\right)\right.
\end{aligned}
$$

Further, using inequality (2.2), we have

$$
\begin{aligned}
\delta_{2}\left(T u, T u^{\prime}\right)= & \delta_{2}\left(T R S T u, T R S T u^{\prime}\right) \\
\leq & c \max \left\{\frac{\delta_{2}\left(T u, T u^{\prime}\right)\left\{1+\delta_{2}(T u, T R S T u)\right\}}{1+d_{2}\left(T u, T u^{\prime}\right)},\right. \\
& \frac{\delta_{2}\left(T u^{\prime}, T R S T u\right)\left\{1+\delta_{2}\left(T u, T R S T u^{\prime}\right)\right\}}{1+\delta_{2}\left(T u, T u^{\prime}\right)} \\
& \frac{\delta_{2}\left(T u^{\prime}, T R S T u^{\prime}\right)\left\{1+\delta_{2}(T u, T R S T u)\right\}}{1+\delta_{2}\left(T u, T u^{\prime}\right)},
\end{aligned}
$$




$$
\begin{aligned}
& \left.\delta_{1}\left(R S T u, R S T u^{\prime}\right), \delta_{3}\left(S T u, S T u^{\prime}\right)\right\} \\
\leq & c \max \left\{\frac{\delta_{2}\left(T u, T u^{\prime}\right)\left\{1+\delta_{2}(T u, T u)\right\}}{1+\delta_{2}\left(T u, T u^{\prime}\right)}\right. \\
& \frac{\delta_{2}\left(T u^{\prime}, T u\right)\left\{1+\delta_{2}(T u, T u)\right\}}{1+\delta_{2}\left(T u, T u^{\prime}\right)} \\
& \frac{\delta_{2}\left(T u^{\prime}, T u^{\prime}\right)\left\{1+\delta_{2}(T u, T u)\right\}}{1+\delta_{2}\left(T u, T u^{\prime}\right)} \\
& \left.d_{1}\left(u, u^{\prime}\right), \delta_{3}\left(S T u, S T u^{\prime}\right)\right\} \\
= & c \max \left\{d_{1}\left(u, u^{\prime}\right), \delta_{3}\left(S T u, S T u^{\prime}\right)\right\}
\end{aligned}
$$

Hence we have

$$
d_{1}\left(u, u^{\prime}\right) \leq c \delta_{3}\left(S T u, S T u^{\prime}\right)
$$

Finally on using inequality (2.3), we have

$$
\begin{aligned}
d_{1}\left(u, u^{\prime}\right)= & c \delta_{3}\left(S T u, S T u^{\prime}\right) \\
\leq & c \delta_{3}\left(S T R S T u, S T R S T u^{\prime}\right) \\
\leq & c^{2} \max \left\{\frac{\delta_{3}\left(S T u, S T u^{\prime}\right)\left\{1+\delta_{3}(S T u, S T R S T u)\right\}}{1+\delta_{3}\left(S T u, S T u^{\prime}\right)},\right. \\
& \frac{\delta_{3}\left(S T u^{\prime}, S T R S T u\right)\left\{1+\delta_{3}\left(S T u, S T R S T u^{\prime}\right)\right\}}{1+\delta_{3}\left(S T u, S T u^{\prime}\right)} \\
& \frac{\delta_{3}\left(S T u^{\prime}, S T R S T u^{\prime}\right)\left\{1+\delta_{3}(S T u, S T R S T u)\right\}}{1+\delta_{3}\left(S T u, S T u^{\prime}\right)}, \\
& \left.\delta_{1}\left(R S T u, R S T u^{\prime}\right), \delta_{2}\left(T R S T u, T R S T u^{\prime}\right)\right\} \\
= & c^{2} d_{1}\left(u, u^{\prime}\right)
\end{aligned}
$$

Since $c<1$, it follows that $u=u^{\prime}$ and the uniqueness of $u$ follows.

Similarly, it can be proved that $v$ is the unique fixed point of $T R S$ and $w$ is the unique fixed point of $S T R$. We finally prove that $R w=u$. To do this, note that $R w=R(S T R w)=R S T(R w)$ and so $R w$ is a fixed point of $R S T$. Since $u$ is the unique fixed point of $R S T$, it follows that $R w=u$. This completes the proof of the theorem. 
Next we prove the following analogous result for compact metric spaces.

Theorem 2.2.Let $\left(X, d_{1}\right),\left(Y, d_{2}\right)$ and $\left(Z, d_{3}\right)$ be compact metric spaces. If $T$ is continuous mapping of $X$ into $B(Y), S$ is a continuous mapping of $Y$ into $B(Z)$ and $R$ is a continuous mapping of $Z$ into $B(X)$ satisfying the inequalities

$$
\begin{aligned}
\delta_{1}\left(R S T x, R S T x^{\prime}\right)< & c \max \left\{\frac{d_{1}\left(x, x^{\prime}\right)\left\{1+\delta_{1}(x, R S T x)\right\}}{1+d_{1}\left(x, x^{\prime}\right)},\right. \\
& \frac{\delta_{1}\left(x^{\prime}, R S T x\right)\left\{1+\delta\left(x, R S T x^{\prime}\right)\right\}}{1+d_{1}\left(x, x^{\prime}\right)}, \\
& \frac{\delta_{1}\left(x^{\prime}, R S T x^{\prime}\right)\left\{1+\delta_{1}(x, R S T x)\right\}}{1+d_{1}\left(x, x^{\prime}\right)}, \\
& \left.\delta_{2}\left(T x, T x^{\prime}\right), \delta_{3}\left(S T x, S T x^{\prime}\right)\right\}
\end{aligned}
$$

$$
\begin{aligned}
\delta_{3}\left(T R S y, T R S y^{\prime}\right)< & c \max \left\{\frac{\delta_{2}\left(y, y^{\prime}\right)\left\{1+\delta_{2}(y, T R S y)\right\}}{1+d_{2}\left(y, y^{\prime}\right)},\right. \\
& \frac{\delta_{2}\left(y^{\prime}, T R S y\right)\left\{1+\delta_{2}\left(y, T R S y^{\prime}\right)\right\}}{1+d_{2}\left(y, y^{\prime}\right)}, \\
& \frac{\delta_{2}\left(y^{\prime}, T R S y^{\prime}\right)\left\{1+\delta_{2}(y, T R S y)\right\}}{1+d_{2}\left(y, y^{\prime}\right)}, \\
& \left.\delta_{2}\left(S y, S y^{\prime}\right), \delta_{3}\left(R S y, R S y^{\prime}\right)\right\}
\end{aligned}
$$

$$
\begin{aligned}
\delta_{3}\left(S T R z, S T R z^{\prime}\right)< & c \max \left\{\frac{d_{3}\left(z, z^{\prime}\right)\left\{1+\delta_{3}(z, S T R z)\right\}}{1+d_{3}\left(z, z^{\prime}\right)},\right. \\
& \frac{\delta_{3}\left(z^{\prime}, S T R z\right)\left\{1+\delta_{3}\left(z, S T R z^{\prime}\right)\right\}}{1+d_{3}\left(z, z^{\prime}\right)}, \\
& \frac{\delta_{3}\left(z^{\prime}, S T R z^{\prime}\right)\left\{1+\delta_{3}(z, S T R z)\right\}}{1+d_{3}\left(z, z^{\prime}\right)}, \\
& \left.\delta_{1}\left(R z, R z^{\prime}\right), \delta_{2}\left(T R z, T R z^{\prime}\right)\right\}
\end{aligned}
$$


for all $x, x^{\prime}$ in $X, y, y^{\prime}$ in $Y$ and $z, z^{\prime}$ in $Z$, where $0 \leq c<1$, then $R S T$ has a unique fixed point $u$ in $X$. TRS has a unique fixed point $v$ in $Y$ and STR has a unique fixed point $w$ in $Z$. Further, $T u=v, S v=w$ and $R w=u$.

Proof. Let us denote the right-hand side of inequalities (2.7), (2.8) and (2.9) by $h\left(x, x^{\prime}\right), k\left(y, y^{\prime}\right)$ and $p\left(z, z^{\prime}\right)$ respectively.

Suppose first of all that there exist $u, u^{\prime}$ in $X$ such that $h\left(u, u^{\prime}\right)=0$. Then it follows immediately that $u=u^{\prime}$ and $R S T u=u$. Then on putting $T u=v, S v=w$, we have $R S v=u \Rightarrow T R S v=T u=v, S T R S v=S T R w=$ $S v=w \Rightarrow R S v=R w=u$.

The result of the theorem therefore holds in this case.

Similarly, if there exist $v, v^{\prime}$ in $Y$ such that $k\left(v, v^{\prime}\right)=0$ or if there exist $w, w^{\prime}$ in $Z$ such that $p\left(w, w^{\prime}\right)=0$, then the results of the theorem also hold.

Now suppose that $h\left(x, x^{\prime}\right) \neq 0$ for all $x, x^{\prime}$ in $X, k\left(y, y^{\prime}\right) \neq 0$ for all $y, y^{\prime}$ in $Y$ and $p\left(z, z^{\prime}\right) \neq 0$ for all $z, z^{\prime}$ in $Z$. Define the function $f$ on $X^{2}$ by

$$
f\left(x, x^{\prime}\right)=\frac{\delta_{1}\left(R S T x, R S T x^{\prime}\right)}{h\left(x, x^{\prime}\right)}
$$

Then $f$ is continuous and since $X \times X$ is compact, $f$ attains its maximum value $c_{1}$. Because of inequality (2.7), $c_{1}<1$ and so

$$
\delta_{1}\left(R S T x, R S T x^{\prime}\right) \leq c_{1} h\left(x, x^{\prime}\right)
$$

for all $x, x^{\prime}$ in $X$.

Similarly, there exist $c_{2}, c_{3}<1$ such that

$$
\delta_{2}\left(T R S y, T R S y^{\prime}\right) \leq c_{2} h\left(y, y^{\prime}\right)
$$

for all $y, y^{\prime}$ in $Y$ and

$$
\delta_{3}\left(S T R z, S T R z^{\prime}\right) \leq c_{3} p\left(z, z^{\prime}\right)
$$

for all $z, z^{\prime}$ in $Z$. It follows that the conditions of Theorem 2.2 are satisfied with $c=\max \left\{c_{1}, c_{2}, c_{3}\right\}$ and so the results of the theorem are again satisfied.

The uniqueness of $\mathrm{u}, \mathrm{v}$ and $\mathrm{w}$ follows easily.

\section{References}

[1] B. Fisher, Fixed points on two metric spaces, Glasnik. Mat. 16(36), 333-337, 1981. 
[2] B. Fisher, Related fixed points on two metric spaces, Math. Sem. Notes Kobe Univ., 10(1) 17-26, (1982).

[3] Nung N. P., A fixed point theorem in three metric spaces, Math. Semin, Notes, Kobe Univ., 11 (1983), 77-79.

[4] R. K. Jain, Fixed points on three metric spaces, Bulletin of Calcutta math. Soc., 87 (1995), 463-466.

[5] R. K. Jain, H.K. Sahu and Brian Fisher, Related fixed point theorems for three metric spaces, Novi Sad. J. Math. 26(1), (1996), 11-17.

[6] R.K. Jain, A. K. Shrivastava and Brian Fisher, Fixed points on three complete metric spaces, Novi Sad J. Math. 27(1), (1997), 27-35.

[7] Brain Fisher and P. P. Murthy, Related fixed point theorems for two pairs of mappings on two metric space, Kyungpook Math. J. 37 (1997), 343-347.

[8] Fisher B, R. K. Namdeo, N.K. Tiwari and KenanTas, Related fixed point theorems on two complete and compact metric spaces, Internet. J. Math. and Math. Sci. 21(3), (1998), 559-564.

[9] M. Ranjit and Y. Rohen, Related fixed point theorems for two pairs of mappings on two complete and compact metric spaces, Proc. of the Nat. Sem. on Analysis (1999), 64-72.

[10] Y. Rohen, Related fixed point theorems for set-valued mappings on two complete and compact metric spaces, Int. J. of Math. Sc. and Engg. Appls.(IJMSEA), 3(I) (2009), 239-247.

[11] Y. Rohen, Related fixed point theorems for two pairs of set-valued mappings on two complete and compact metric spaces, Int. J. of Math. Sc. and Engg. Appls (IJMSEA) 3(II) (2009), 137-145.

[12] Brain Fisher and Duran Turkoghu, Related fixed points for set-valued mappings on two metric spaces, Internet J. of Math. and Math. Sci. 23(30), (2000), 205-210.

[13] Sarika Jain and Brain Fisher, A related fixed point theorem for three metric spaces, Hecettepe J. of Math. and Stat. 31 (2002), 19-24.

[14] R. K. Namdeo and Brian Fisher, Related fixed point theorems for two pairs of set valued mappings on two complete and compact metric spaces, Indian Journal of math., 46 (2-6), (2004), 161-171.

[15] V. K. Chourasia and Brian Fisher, Related fixed points for two pairs of set valued mappings on two metric spaces, Hacettepe J. of Math. Stat., 32 (2003), 27-32.

[16] Abdelkrim Aliouche and Brian Fisher, A related fixed point theorem for two pairs of mappings on two complete metric spaces, Hacetepe J. of Math. and Stat, 34 (2005), 39-45.

[17] Abdelkrim Aliouche and Brian Fisher,A related fixed point theorem for two pairs of mappings on two complete metric spaces without continuity, Stud. Cer. St. Ser. Matematica Universitatea Bacau,15 (2005), 1-9.

[18] R. K. Namdeo and Brian Fisher, A related fixed point theorem for two pairs of mappings on two metric spaces, Nonlinear Analysis Forum, 8(1), (2003) 23-27.

[19] R. K. Namdeo and Brian Fisher, A related fixed point theorem for three pairs of mappings on three metric spaces, Thai Journal of Mathematics, 7(1), (2009), 129-135. 
[20] R. K. Namdeo and Brian Fisher, A related fixed point theorem for three pairs of mappings on three complete metric spaces, Mathematical Sciences, 4(2), (2010), 221-232.

[21] R. K. Jain, H. K. Sahu and Brain Fisher, A related fixed point theorem on three metric spaces, Kyungpook Math. J. 36 (1996), 151-154.

[22] Luljeta Kakina and Kristaq Kakina, A related fixed point theorem on four metric spaces, Int. J. Math. Anal 3 (32), (2009), 1559-1568.

[23] A. K. Chaubey, M. D. Gupta and D. P. Sahu, A related fixed point theorem on five metric spaces, Journal of International Academy of Physical Sciences, 15(1), (2011), 69-84.

[24] Luljeta Kakina, Fixed point theorems in three metric spaces, Int. J. of Math. Anal. 3(13), 2009, 613-626.

[25] Sampada Navshinde, J. Achari and Brian Fisher, Related fixed point theorems for three metric spaces (II), Mathematica Moravica, 15(2), 2011, 11-17.

[26] Taieb Hamaizia and Abdelkrim Aliouche, Related fixed point on two metric spaces, Palestine Journal of Mathematics, 2(1), 2013, 100-103.

[27] Vishal Gupta, Related fixed point theorems for four complete metric spaces, Acta. Univ. Sapientiae Mathematica, 5(2), 2013, 147-156.

[28] R.K. Saini, Seema Devi and Naveen Gulati, Fixed point theorem on two complete metric spaces, Int. J. of Emerging trends in Eng. and Dev. 3(6), 2013, 488-493.

[29] Karim Chaira, El-Miloudi Marhrani, Some related fixed points theorems for a pair of mappings on two metric spaces, Int. J. of Pure and applied Math. 93(20), 2014, 191200.

[30] Ismat Beg and Sunny Chauhan, Related fixed point of set-valued mappings in three menger spaces, International Journal of Analysis, (2013) Article ID $\mathbf{7 3 6 4 5 1 .}$

[31] Sunny Chauhan, Ismat Beg and B. D. Pant, A related fixed point theorem in two menger spaces, Gazi University Journal of Science, 27(1), (2014) 659-662.

[32] R. C. Dimri and M. Sharma, A related fixed point theorem in three menger spaces, Fixed point theory, 4(1), 2014, 48-59.

[33] D. Turkoglu and B. Fisher, Related fixed points for set-valued mappings on two uniform spaces, Int. J. Math and Math. Sci. 69 (2003), 3783-3791.

[34] L. Bishwakumar and Y. Rohen, Related fixed points for two pairs of mappings on two uniform spaces, Proc. of Math. Soc. BHU 26 (2010), 1-9.

[35] Yumnam Rohen and L. Bishwakumar, Related fixed point theorem for a pair of mappings on two uniform spaces, Int. J. of Math.Sci. and Engg.Appls.(IJMSEA), 5(III) 2011, 269280.

[36] L. Ibeni and Yumnam Rohen, Related fixed points theorems for three set-valued mappings on three uniform spaces, Int. J. of Math. Analysis 6(9) 2012, 415-427.

[37] Y. Rohen, L. Bishwakumar and B. Fisher, Related fixed point theorem for two pairs of set-valued mappings on two uniform spaces, Int. J. of Math. Archive, 3(4), 2012, 1597-1605.

[38] Valeriu Popa, Fixed points on two complete metric spaces, Review of Research, Faculty of Science, Math. Series, Univ. of Novi. Sad 21(1) (1991), 83-93. 
[39] Y.J. Cho, S.M. Kang and S.S Kim, Fixed points in two metric spaces, Novi. Sad J. Math, 29(1) (1999), 47-53.

[40] Valeriu Popa, Two general fixed point theorems on three complete metric spaces, Novi. Sad J. Math, 30(1), (2000), 43-50.

[41] Valeriu Popa, A General fixed point theorem for two pairs of mappings on two metric spaces, Novi. Sad. J. Math, 35(2), (2005), 79-83.

[42] Y. Rohen and L. Bishwakumar, Related fixed point theorems on three complete metric spaces, Proc. of Math. Soc.,BHU, 25(2009), 41-45.

[43] Luljeta Kakina and Kristaq Kakina, Generalised fixed point theorems in two metric spaces under implicit relations, Int. J. of Math. Analysis, 4(30) 2010, 1483-1489.

[44] Kristaq Kakina and Luljeta Kakina, Generalised fixed point theorems in three metric spaces under implicit relations, Int. J. of Math. Analysis, 4(40)2010, 1995-2004.

[45] Luljeta Gjoni and Kristaq Kakina, A related fixed point theorems for four mappings on four complete metric spaces, AKTET Journal of Institute ALB-Shkenca 3(IV), 2011, 535-542.

[46] Abdelkrim Aliouche, Faical Merghadi and Brian Fisher, Related fixed point theorems via implicit relation of integral type, Mathematical sciences, 2(1) 2008, 105-121.

[47] Faycal Merghadi, Abdelkrim Aliouche and Brian Fisher, A related fixed point theorem in N complete metric spaces, Acta Univ. Apulensis, 19 (2009), 91-99.

[48] B. Fisher and K. P. R. Rao, A related fixed point theorems on three metric spaces, Hacettepe J. of Math and Stat., 36(2) 2007, 143-146.

[49] L. Bishwakumar and Y. Rohen, Related fixed point theorem for mappings on three metric spaces, American J. of Applied Math. and Stat, 2(4)2014, 244-245.

[50] Zaheer K. Ansari, Manish Sharma and Arun Garg, Related fixed point theorems on three metric spaces, Int. J. Contemp. Math. Sciences, 5(42), 2010, 2059-2064.

[51] Rajesh Shrivastava, Kiran Rathore and K. Qureshi, A fixed point theorem on three metric spaces, Int. J. of Theoretical and Applied Sc. 4(1), 2012, 58-59.

[52] M. Aamri, A. Bassou , S. Bennani and D. El Moutawakil, Some related fixed point theorems on two symmetric spaces, Journal of pure and Applied Mathematics: Advances and Applications, 2(1), 2009, 107-119.

[53] M. Aamri, A. Bassou, S. Bennani and D. El Moutawakil,Related fixed point theorems for two pairs of mappings on two symmetric spaces, Bulletin of Mathematics analysis and Applications, 4(3), 2012, 43-47.

[54] Sushil Sharma, Bhavma Deshpande and Deepti Thakur, Related fixed point theorems for four mappings on two fuzzy metric spaces, Int. J. Pure and Appl. Math. 41(2), 2007, 241-250.

[55] Sushil Sharma, Prashant Tilwankar, Related fixed point theorem for six mappings on three fuzzy metric spaces, Kyungpook Math. J. 51 (2011) 365-374.

[56] Sandeep Bhatt, Pankajkumar Mishra and Shruti Chaukiyal, Related fixed points in three metric spaces, IJSTM, 2(3), 2011, 60-66.

[57] T. K. Samanta, Sumit Mohinta and Iqbal H. Jebril, Related fixed point theorems in fuzzy metric spaces, Int. J. of open problems in Computational Math,5(3), 2012, 
[58] Faycel Merghadi and Abdelkrim Aliouche, A related fixed point theorems in three instituitionistic fuzzy metric spaces, J. Math. Comp. Sci, 2 (6) 2012, 1573-1587. 